\title{
Sex differences in investigation results and treatment in subjects referred for investigation of chest pain
}

\author{
Y Wong, A Rodwell, S Dawkins, S A Livesey, I A Simpson
}

\begin{abstract}
Objective-To evaluate differences in investigation results and treatment between men and women referred for diagnostic treadmill exercise testing and coronary arteriography.

Design-Cohort study.

Setting-Tertiary cardiology centre.

Subjects-1522 subjects referred by primary care physicians to an open access chest pain clinic for initial investigation of chest pain, of whom 485 were subsequently referred for coronary arteriography; and a similar cohort of 107 subjects referred directly by secondary care physicians for diagnostic coronary arteriography.

Main outcome measures-Rates of positive exercise tests and rates for referral for arteriography and revascularisation according to sex.

Results-Overall, women were less likely to be referred for arteriography and revascularisation than men. However, men were more likely to have positive exercise tests, and for various exercise test diagnostic end points men were also more likely to have significant coronary artery disease. After taking this into account, there was no sex difference in referral rates for arteriography or revascularisation.

Conclusions-There was no evidence of a sex bias resulting in inappropriate underinvestigation or undertreatment of women. However, the positive predictive value of treadmill exercise testing is low for women and further research is needed into how best to investigate women with chest pain.
\end{abstract}

(Heart 2001;85:149-152)

Keywords: sex differences; exercise test; chest pain

Numerous studies have shown that women with chest pain and acute coronary syndromes are less likely to be investigated by coronary arteriography ${ }^{1-3}$ or to be treated by percutaneous transluminal coronary angioplasty (PTCA) or coronary artery bypass grafting (CABG) than men. ${ }^{4-6}$ One explanation is that there is an inappropriate sex bias resulting in underinvestigation and undertreatment of women. However, chest pain in womenparticularly in younger women-is less likely to be associated with atheromatous coronary artery disease. It is therefore possible that lower rates of arteriography and revascularisation are because a larger proportion of women have normal findings or less severe disease on previous non-invasive assessment. ${ }^{7}$ The original report of sex bias used nuclear exercise testing for the initial assessment of disease severity and gave convincing evidence that women were less likely to be referred for arteriography. ${ }^{1}$ However, other studies can be criticised because crude rates of arteriography and revascularisation were used without taking preliminary markers of disease severity into account. ${ }^{256}$

In this study, we investigated a cohort of subjects referred to an open access chest pain clinic for initial assessment by treadmill exercise testing, and, using various diagnostic end points, we looked for possible sex bias in subsequent referral for arteriography or myocardial perfusion imaging. For subjects who then had arteriography, we also investigated for possible differences in revascularisation rates. As the subjects referred to an open access clinic may not be representative of all patients, we also investigated a separate cohort referred for arteriography by secondary care physicians.

\section{Methods}

Subjects were consecutive patients referred by primary care physicians to our open access chest pain clinic for diagnostic exercise testing between December 1997 and April 2000. Subjects were included if they had not previously had an exercise test, coronary arteriography, PTCA, or CABG. A nurse recorded demographic data onto an electronic database, along with duration of the exercise test, the occurrence of pain during the procedure, and any ECG changes. Tests were supervised by specialist cardiology registrars who decided at the time, subject to subsequent confirmation by consultants, whether or not to refer for arteriography or myocardial perfusion imaging. Using the same inclusion criteria, we also studied a second cohort of subjects referred directly by secondary care physicians; these patients had had arteriography during a three month period from October 1998.

Cardiac catheterisation results and decisions regarding revascularisation were obtained from electronically stored discharge letters up to the end of August 2000. Significant coronary artery disease was defined as the presence of at least one lesion causing at least $50 \%$ stenosis. 
Table 1 Exercise test findings and referral rates for coronary arteriography and myocardial perfusion imaging for subjects from the open access chest pain clinic

\begin{tabular}{|c|c|c|c|c|c|c|c|c|c|}
\hline \multirow[b]{2}{*}{ Exercise test finding } & \multicolumn{3}{|c|}{ Frequency (\%) } & \multicolumn{3}{|c|}{ Referred for coronary arteriography (\%) } & \multicolumn{3}{|c|}{ Referred for myoview scan (\%) } \\
\hline & $\begin{array}{l}\text { Male } \\
(n=921)\end{array}$ & $\begin{array}{l}\text { Female } \\
(n=601)\end{array}$ & OR $(95 \% C I)$ & $\begin{array}{l}\text { Male } \\
(n=286)\end{array}$ & $\begin{array}{l}\text { Female } \\
(n=137)\end{array}$ & OR $(95 \% C I)$ & $\begin{array}{l}\text { Male } \\
(n=76)\end{array}$ & $\begin{array}{l}\text { Female } \\
(n=31)\end{array}$ & OR $(95 \% C I)$ \\
\hline$\geqslant 2 \mathrm{~mm} \mathrm{ST}$ depression & 14.3 & 5.5 & $2.9(1.9 \text { to } 4.3)^{\star \star}$ & 90.2 & 90.9 & $0.9(0.2$ to 3.4$)$ & 0.8 & 0 & \\
\hline$<2 \mathrm{~mm} \mathrm{ST}$ depression & 15.4 & 14.1 & $1.1(0.8$ to 1.5$)$ & 69.0 & 68.2 & $1.0(0.6$ to 1.8$)$ & 0.7 & 10.6 & $0.1(0.0 \text { to } 0.5)^{\star \star}$ \\
\hline$\geqslant 1 \mathrm{~mm} \mathrm{ST}$ depression & 23.3 & 13.5 & $2.0(1.5 \text { to } 2.6)^{\star \star}$ & 85.1 & 85.0 & $1.0(0.5$ to 2.1$)$ & 0.5 & 1.2 & $0.4(0.0$ to 6.0$)$ \\
\hline$<1 \mathrm{~mm} \mathrm{ST}$ depression & 6.4 & 6.3 & $1.0(0.7$ to 1.5$)$ & 57.6 & 52.6 & $1.2(0.5$ to 2.8$)$ & 1.7 & 21.1 & $0.1(0.0 \text { to } 0.5)^{\star \star \star}$ \\
\hline Other ECG changes $\dagger$ & 2.3 & 2.5 & $0.9(0.5$ to 1.8$)$ & 66.7 & 46.7 & $2.3(0.6$ to 8.9$)$ & 0 & 13.3 & $0.9(0.7$ to 1.1$)$ \\
\hline Pain but no ECG change & 11.1 & 10.6 & $1.0(0.8$ to 1.5$)$ & 46.1 & 37.5 & $1.4(0.8$ to 2.7$)$ & 3.9 & 12.5 & $0.3(0.1 \text { to } 1.0)^{\star}$ \\
\hline No pain and no ECG change & 56.9 & 67.2 & $0.6(0.5 \text { to } 0.8)^{\star \star}$ & 9.5 & 9.4 & $1.0(0.7$ to 1.6$)$ & 3.2 & 7.9 & $0.4(0.2 \text { to } 0.7)^{\star \star \star}$ \\
\hline \multicolumn{10}{|l|}{ Stage exercise test stopped $\ddagger$} \\
\hline Stage I and II & 16.0 & 29.8 & $0.4(0.3 \text { to } 0.6)^{\star \star}$ & 29.3 & 17.9 & $1.9(1.0$ to 3.8$)$ & 9.8 & 15.2 & $0.6(0.2$ to 1.5$)$ \\
\hline Stage III and IV & 84.0 & 70.2 & $2.2(1.6 \text { to } 3.1)^{\star \star}$ & 5.1 & 4.5 & $1.1(0.6$ to 2.3$)$ & 2.1 & 3.4 & $0.6(0.2$ to 1.5$)$ \\
\hline
\end{tabular}

†ST elevation, $\mathrm{T}$ wave inversion, or arrhythmia (in the absence of ST depression).

$\ddagger$ For subjects without any ECG changes or pain and whose exercise test was the full Bruce protocol (511 men and 375 women).

${ }^{\star} \mathrm{p}<0.05 ;{ }^{\star \star} \mathrm{p}<0.01 ;{ }^{\star \star \star} \mathrm{p}<0.001$.

$\mathrm{CI}$, confidence interval; OR, odds ratio.

Prognostic coronary artery disease (disease for which CABG would be expected to prolong life expectancy) was defined as left main coronary artery disease, three vessel disease, or disease in the proximal left anterior descending coronary artery and one other vessel.

Continuous variables were compared with the two tailed Student $t$ test and categorical variables with the $\chi^{2}$ test and the calculation of odds ratios with $95 \%$ confidence intervals (CI) (SPSS version 9).

\section{Results}

During the study period, 2002 subjects were referred to the open access clinic, of whom 1522 fulfilled the inclusion criteria (table 1). Their mean (SD) age was 56.1 (13.1) and 58.2 (12.2) years for men and women, respectively $(p=0.002)$. The exercise test protocol used was the full Bruce in $95.4 \%$ of men and $93.2 \%$ of women. When overall referral rates for further investigation were considered, women were referred as often as men $(34.6 \%$ v $38.1 \%$ ), but men were more often referred for arteriography $(35.6 \% v 26.1 \%$; odds ratio 1.6 , $95 \%$ CI 1.2 to 2.0 ) while women were more likely to be referred for myocardial perfusion imaging $(8.5 \%$ v $2.5 \%$; odds ratio $3.6,95 \% \mathrm{CI}$ 2.2 to 6.0 ). However, positive exercise tests occurred more often in men, while women were more likely to have tests without ECG changes and pain (table 1). It can be seen that for a variety of exercise test diagnostic end points, referral for arteriography was always as common in women as men but referral rates for myocardial perfusion imaging were sometimes higher in women.

In all, 485 subjects were referred for arteriography from the open access clinic. Among these there was no difference in age between men and women (61.6 (10.1) $v 61.4$ (11.2) years). By the end of August 2000, 423 subjects had been investigated (table 2). A further 25 were waiting, 11 (five women and six men) had declined, three had died, one had developed a serious malignancy, and 22 (six women and 16 men) were lost to follow up. Overall, men were more likely than women to be referred for PTCA or CABG $(59.4 \% v$ $32.8 \%$; odds ratio $3.0,95 \%$ CI 2.0 to 4.6 ) but this was because men had a higher incidence of both significant and prognostic coronary artery disease (table 2). In fact, $56.2 \%$ of women were found to have normal coronary arteries compared with only $16.4 \%$ of men. When this was taken into account, there was no significant difference in revascularisation rates. For subjects with prognostic disease, the referral rates for PTCA and CABG were $11.4 \%$ and $75.6 \%$ for men and $22.7 \%$ and $68.2 \%$ for women. The corresponding rates for significant but nonprognostic disease were $41.4 \%$ and $12.9 \%$ for men and $55.3 \%$ and $10.5 \%$ for women. In contrast to revascularisation rates, differences were found for the positive predictive value of an exercise test. If an exercise test was defined as positive when there was at least $2 \mathrm{~mm}$ of ST depression, the positive predictive value (posttest likelihood of coronary artery disease) was $95.2 \%$ for men but only $72 \%$ for women. These values are only close approximations, as 15 subjects $(9.1 \%)$ with positive tests were not referred for arteriography (table 1) and we do not know whether they had coronary artery disease or not (four of these subjects were not referred because they had severe peripheral vascular or respiratory disease, and the remainder had few symptoms with good exercise tolerance). Similarly, we did not calculate negative predictive values because the majority of subjects without significant ECG changes were not referred for arteriography. Nevertheless, it can be seen that for most exercise test diagnostic end points, men were more likely than women to have coronary artery disease (table 2).

The cohort of subjects referred by secondary care physicians was smaller than that referred from the open access clinic (table 3 ). However, baseline characteristics were similar in that there were more men than women, there was no sex difference in age (59.1 (9.2) $v 60.8$ (8.2) years), and a significant proportion of subjects did not have ECG changes on exercise testing. Once again, men were more likely than women to have coronary artery disease and after taking this into consideration there was no significant difference in revascularisation rates. For subjects with significant or prognostic coronary artery disease, $65.7 \%$ of men and $50 \%$ of women had revascularisation by CABG or PTCA (odds ratio $1.9,95 \%$ CI 0.6 to 5.7 ). 
Table 2 Coronary artery disease in subjects referred for coronary arteriography from the open access chest pain clinic

\begin{tabular}{|c|c|c|c|c|c|c|c|c|}
\hline \multirow[b]{2}{*}{ Exercise test finding } & \multicolumn{2}{|c|}{ Number of subjects } & \multicolumn{3}{|c|}{$\begin{array}{l}\text { Subjects with significant coronary } \\
\text { artery disease (\%) }\end{array}$} & \multicolumn{3}{|c|}{$\begin{array}{l}\text { Subjects with prognostic coronary } \\
\text { artery disease (\%) }\end{array}$} \\
\hline & Male & Female & Male & Female & OR $(95 \% C I)$ & Male & Female & OR $(95 \% C I)$ \\
\hline All subjects & 286 & 137 & 83.6 & 43.8 & $6.5(4.1 \text { to } 10.3)^{\star \star}$ & 43.0 & 16.1 & $3.9(2.4 \text { to } 6.6)^{\star \star}$ \\
\hline$\geqslant 2 \mathrm{~mm}$ ST depression & 104 & 25 & 95.2 & 72.0 & $7.7(2.2 \text { to } 26.9)^{\star \star}$ & 56.7 & 16.0 & $6.9(2.2 \text { to } 21.5)^{\star \star}$ \\
\hline$<2 \mathrm{~mm} \mathrm{ST}$ depression & 89 & 52 & 87.6 & 51.9 & $6.6(2.9 \text { to } 15.1)^{\star \star}$ & 51.7 & 21.2 & $4.0(1.8 \text { to } 8.7)^{\star \star}$ \\
\hline$\geqslant 1 \mathrm{~mm} \mathrm{ST}$ depression & 163 & 60 & 93.9 & 65.0 & $8.2(3.6 \text { to } 18.9)^{\star \star}$ & 56.4 & 21.7 & $4.7(2.4 \text { to } 9.3)^{\star \star}$ \\
\hline$<1 \mathrm{~mm} \mathrm{ST}$ depression & 30 & 17 & 80.0 & 35.3 & $7.3(1.9 \text { to } 27.9)^{\star \star \star}$ & 43.3 & 11.8 & $5.7(1.1 \text { to } 29.6)^{\star}$ \\
\hline Other ECG changest & 14 & 6 & 78.6 & 50.0 & $3.7(0.5$ to 28.4$)$ & 28.6 & 0 & \\
\hline Pain but no ECG change & 41 & 23 & 70.7 & 21.7 & $8.7(2.6 \text { to } 28.8)^{\star \star}$ & 14.6 & 13.0 & $1.1(0.3$ to 5.1$)$ \\
\hline No pain and no ECG change & 38 & 31 & 57.9 & 22.6 & $4.7(1.6 \text { to } 13.6)^{\star \star \star}$ & 21.1 & 12.9 & $1.8(0.5$ to 6.7$)$ \\
\hline \multicolumn{9}{|l|}{ Stage exercise test stopped $\ddagger$} \\
\hline Stage I and II & 18 & 17 & 66.7 & 29.4 & $4.8(1.1 \text { to } 20.1)^{\star}$ & 33.3 & 17.6 & $2.3(0.5$ to 11.4$)$ \\
\hline Stage III and IV & 16 & 9 & 43.8 & 11.1 & $6.2(0.6$ to 62.2$)$ & 6.3 & 11.1 & $0.5(0.0$ to 9.7$)$ \\
\hline
\end{tabular}

†ST elevation, T wave inversion or arrhythmia (in the absence of ST depression).

$\ddagger$ For subjects without any ECG changes or pain and whose exercise test was the full Bruce protocol.

${ }^{\star} \mathrm{p}<0.05 ;{ }^{\star \star} \mathrm{p}<0.01 ;{ }^{\star \star \star} \mathrm{p}<0.001$.

\section{Discussion}

For certain anatomical patterns of coronary artery disease, CABG is of prognostic benefit ${ }^{8}$ and arteriography is important for obtaining anatomical data. A sex bias against women may therefore result in inappropriate withholding of life saving treatment. In the first reports of sex bias, it was postulated that women may have been under investigated because opinion at the time was that angina carried a better prognosis in women ${ }^{10}$ and that women had more complications and benefited less following surgery. ${ }^{11}$ However, more recent studies report that such a bias still exists. ${ }^{6}$ It has also been suggested that a sex bias may arise because women were more likely than men to decline a major procedure. ${ }^{2}$ We found, however, that only a very small proportion of subjects of either sex refused further investigation. Finally, it is possible that women with chest pain are less likely to undergo arteriography and revascularisation because they have less severe disease.

The treadmill exercise test is the classic method for initial assessment of chest pain. A test can be interpreted as being positive if $2 \mathrm{~mm}$ of ST depression on the ECG is achieved, but other end points include lesser degrees of ST depression and the occurrence of symptoms. Prognostic scores taking these factors into account have been devised but have not been widely validated. ${ }^{12}$ Therefore there is some subjectivity in interpreting the significance of exercise test results. For instance in this study, while the vast majority of subjects with $2 \mathrm{~mm}$ of ST depression were referred for arteriography, a varying proportion

Table 3 Exercise test findings and coronary artery disease in subjects referred for coronary arteriography by secondary care physicians

\begin{tabular}{|c|c|c|c|}
\hline & \multicolumn{2}{|c|}{ Percentage of subjects } & \multirow[b]{2}{*}{ OR $(95 \% C I)$} \\
\hline & $\begin{array}{l}\text { Men } \\
(n=76)\end{array}$ & $\begin{array}{l}\text { Women } \\
(n=31)\end{array}$ & \\
\hline \multicolumn{4}{|l|}{ Exercise test findings } \\
\hline$\geqslant 2 \mathrm{~mm} \mathrm{ST}$ depression & 34.2 & 22.6 & $1.8(0.7$ to 4.7$)$ \\
\hline$<2 \mathrm{~mm} \mathrm{ST}$ depression & 22.4 & 35.5 & $0.5(0.2$ to 1.3$)$ \\
\hline Pain and no ECG changes & 18.4 & 9.7 & $2.1(0.6$ to 5.2$)$ \\
\hline No pain and no ECG changes & 25.0 & 32.3 & $0.7(0.3$ to 1.4$)$ \\
\hline \multicolumn{4}{|l|}{ Cardiac catheterisation results } \\
\hline Normal coronary arteries & 7.9 & 48.4 & $0.1(0.0 \text { to } 0.6)^{\star \star}$ \\
\hline Significant coronary artery disease & 92.1 & 51.6 & $10.9(3.7 \text { to } 32.6)^{\star \star}$ \\
\hline Prognostic coronary artery disease & 46.1 & 16.1 & $4.4(1.5 \text { to } 12.8)^{\star \star \star}$ \\
\hline
\end{tabular}

${ }^{\star \star} \mathrm{p}<0.01 ;{ }^{\star \star \star} \mathrm{p}<0.001$. of subjects with other findings was referred. A sex bias may therefore arise if thresholds for diagnosing severe disease are higher for women. However, we found no evidence for such a bias, and for each diagnostic end point referral rates for arteriography were equal in both sexes.

It has been claimed that, as well as being less likely to be referred for arteriography and revascularisation, women who are referred are older and have more severe disease than their male counterparts and that this reflects delay in referral. ${ }^{4}$ In our open access clinic cohort, women were older but this is to be expected as coronary artery disease presents earlier in men. However, in both cohorts of subjects undergoing arteriography, not only was age the same in the two sexes but women were less likely to have significant coronary artery disease and more likely to have normal coronary arteries. The incidence of normal coronary arteries among women in our study was similar to that in other series where subjects have had arteriography for diagnostic purposes. ${ }^{8}$

\section{CONCLUSIONS}

We found no evidence of a sex difference in referral for arteriography or revascularisation. The sex differences that were identified suggest that women presenting with chest pain are less likely to have a positive exercise test, and among those who do have a positive exercise test, women are less likely to have coronary artery disease than men, as has previously been reported. ${ }^{13}$ Although the question of whether sex bias exists is important, a more relevant question seems to be how best to investigate women with chest pain. In our open access chest pain cohort, $56.2 \%$ of women undergoing arteriography had normal coronary arteries. However, arteriography remains an important diagnostic tool as the positive predictive value of treadmill exercise testing-the most widely available non-invasive method for assessing chest pain-is low in women.

\footnotetext{
1 Tobin JN, Wassertheil-Smoller S, Wexler JP, et al. Sex bias in considering coronary bypass surgery. Ann Intern Med 1987;107:19-25.

2 Ayanian JZ, Epstein AM. Differences in the use of procedures between women and men hospitalised for corprocedures between women and men hospitalised for

3 Steingart RM, Packer M, Hamm P, et al. Sex differences in Steingart RM, Packer M, Hamm P, et al. Sex differences in
the management of coronary artery disease. $N$ Engl $f$ Med 1991;325:226-30.
} 
4 Khan SS, Nessim S, Gray R, et al. Increased mortality of women in coronary artery bypass surgery: evidence for referral bias. Ann Intern Med 1990;112:561-7.

5 Petticrew $M$, McKee $M$, Jones J. Coronary artery surgery: are women discriminated against? BMf 1993;306:1164-6.

6 Majeed FA, Cook DG. Age and sex differences in the management of ischaemic heart disease. Public Health 1995; 110:7-12.

7 Mark DB, Shaw LK, DeLong ER, et al. Absence of sex bias in the referral of patients for cardiac catheterization. $N$ Engl f Med 1994;330:1101-6.

8 Kennedy JW, Killip T, Fisher LD, et al. The clinical spectrum of coronary artery disease and its surgical and medical management. Circulation 1982;66(suppl 3):16-23.
9 Lerner DJ, Kannel WB. Patterns of coronary heart disease morbidity and mortality in the sexes: a 26 year follow-up of the Framingham population. Am Heart f 1986;111:383-90.

10 Wenger NK. Gender, coronary artery disease, and coronary bypass surgery. Ann Intern Med 1990;112:557-8.

11 Loop FD, Golding LR, Macmillan JP, et al. Coronary artery surgery in women compared with men: analyses of risks and long term results. F Am Coll Cardiol 1983;2:383-90.

12 Mark DB, Hlatky MA, Harrell FE, et al. Exercise treadmill score for predicting prognosis in coronary artery disease. Ann Intern Med 1987;106:793-800.

13 Sketch MH, Mohiuddin SM, Lynch JD, et al. Significant sex differences in the correlation of electrocardiographic exercise testing and coronary arteriograms. Am f Cardiol 1975; 36:169-73.

\section{IMAGES IN CARDIOLOGY}

\section{Echocardiographic diagnosis of Bland-White-Garland syndrome}
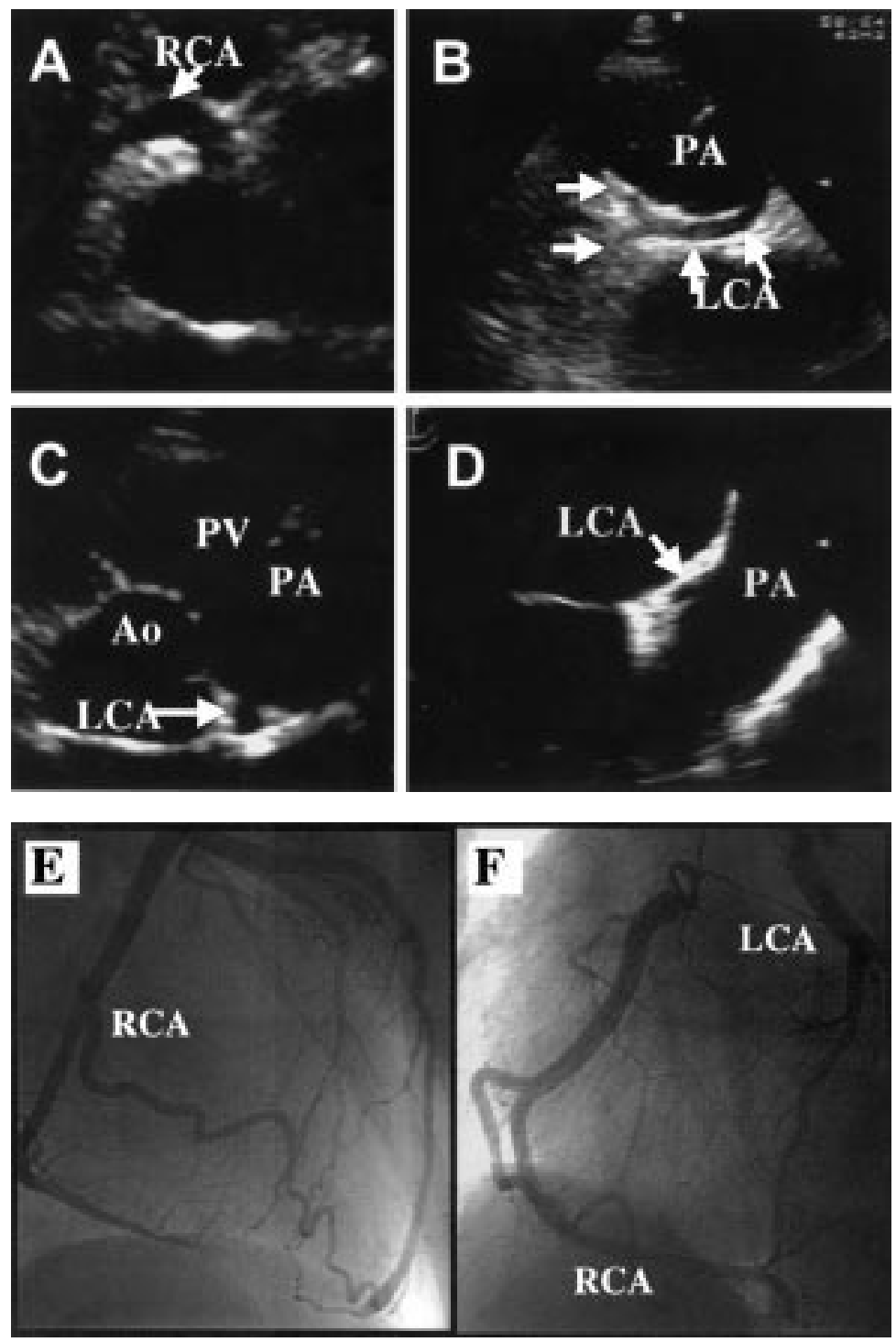

A 23 year old man without any prior history or symptoms of heart disease was referred to the adult echocardiography laboratory for evaluation of a systolic heart murmur with its maximal intensity at the apex. Echocardiography showed a dilated left ventricle with severely impaired contractile function and moderate mitral regurgitation. When imaging the proximal aorta (Ao) in its short axis, an enlarged proximal portion of the right coronary artery was identified arising from its normal origin (A). The left main coronary artery (LCA) could not been seen from this view but the LCA with proximal left anterior descending (LAD) and left circumflex (LCX) branches were found to originate from the pulmonary trunk (PA) on transthoracic (A, B, C) and multiplane transoesophageal (D) echocardiography (PV, pulmonary artery valve).

Coronary angiography confirmed the diagnosis of Bland-White-Garland syndrome and severely impaired left ventricular function with anterior hypokinesia. Following injection of contrast into the right coronary artery $(\mathrm{E}, \mathrm{F})$ retrograde filling of the left coronary artery system via collateral vessels originating from the RCA was also noted, partially opacifying the pulmonary artery. The patient was referred for successful surgical correction by direct coronary reimplantation.

A HANSEN D MERELES H KUECHERER 